WellBeing International

WBI Studies Repository

1972

\title{
Grooming Behavior and Competitive Dominance in the Albino Rat
}

Irwin M. Spigel

University of Toronto

Susan Trivett

University of Toronto

David Fraser

University of Glasgow

Follow this and additional works at: https://www.wellbeingintlstudiesrepository.org/socbeh

Part of the Animal Studies Commons, Behavior and Ethology Commons, and the Comparative Psychology Commons

\section{Recommended Citation}

Spigel, I. M., Trivett, S., \& Fraser, D. (1972). Grooming behavior and competitive dominance in the albino rat. Journal of Comparative and Physiological Psychology, 78(3), 409.

This material is brought to you for free and open access by WellBeing International. It has been accepted for inclusion by an authorized administrator of the WBI Studies Repository. For more information, please contact wbisr-info@wellbeingintl.org.

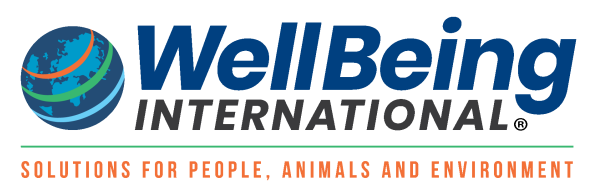




\title{
Grooming Behavior and Competitive Dominance in the Albino Rat ${ }^{\dagger}$
}

\author{
Irwin M. Spigel ${ }^{1}$, Susan Trivett $^{1}$, and David Fraser $^{2}$ \\ ${ }^{1}$ University of Toronto \\ ${ }^{2}$ University of Glasgow
}

\begin{abstract}
An experiment sought to compare dominance manifested in water competition under two levels of deprivation, with grooming activity in a non-deprived state. While competitive dominance was significantly related to motivational level, grooming emerged as a more stable indicator of social ascendance, and did not require prior manipulation of a biological state. The implications of this observation for broader aspects of social motivation arc discussed.
\end{abstract}

Arena competition for food and water has long been utilized for the determination of dominance (e.g., Bruce, 1941) in the pair relationships of rodents. It was apparent from these early studies that dominance, as measured by consummatory behavior, was highly correlated with the magnitude of deprivation of individual animals.

More recently, a form of "dominance tube" (Hsiao \& Schreiber, 1968; Lindzey, Manosevitz, \& Winston, 1961, 1966; Uyeno, 1971; Uyeno \& White, 1967) has been employed with various reinforcement contingencies to explore dominance relationships. While the relationship between motivational state and dominance was also evident in the tube situation (Hsiao \& Schreiber, 1968) observations of dominance with the later procedures were often inconsistent with those of arena competition (Lindzey et al., 1966). It would further appear from the investigations of Becker (1966) and Ingeborg and Gerall (1968) that such factors as emotionality and general activity level may obscure the relevant behavior patterns and, together with motivational level, prevent a more accurate assessment of dominance with these traditional procedures.

The significance of fighting in adult male rats in the determination of social relationships has been emphasized by Barnett (1967, pp. 91-92). Baenninger (1966) has likewise demonstrated correlation between dominance and the number of aggressive encounters. A great deal of pilot observation in our own laboratory has subsequently suggested that grooming behavior is particularly more manifest in male rats which have won fights, independent of any other drive state. Long periods of pair observation suggested that fights often began when one animal of a pair resisted the efforts of the other to groom, and the winner thus established what might be described as the right to groom. The current experiment was designed to explore the relationship between grooming and the more traditional manifestations of dominance in arena competition for water, under two levels of motivation. 
Since grooming behavior in the rat includes a complex sequence of activities, only the most gross manifestations of this behavior were measured and recorded-namely, the crawling over and under the other by the grooming rat, and its actual "chewing-like" movements at the back, back of the head, and genital area of the other. The simple brushing, "nosing," and sniffing behaviors, which appeared to be preliminary activities, were not recorded.

\section{METHOD}

\section{Subjects}

Twenty-eight male Wistar rats, colony reared, at an age of 107 days were used in the study. All were housed individually on a reversed light cycle with ad-lib food availability.

\section{Apparatus}

Two separate chambers were used. The water-competition arena was a 12-in.-sq. box with a water bottle fixed at one corner, the tube within easy reach of the rats. The grooming test chamber was a $24 \times 24$ in. box, 18 in. high. Both boxes were painted gray.

\section{Procedure}

The experiment consisted of a four-stage sequence. In the first, an habituation stage which lasted for 10 days, the rats were placed on 22-hr, water deprivation and individually given 3-min. daily sessions in the arena. Thirty minutes later, back in their home cages, they were given ad-lib water for $2 \mathrm{hr}$. On the final day, the rats were rank ordered on the basis of body weight, paired in that order, and the pairs then randomly assigned to either a high (23-hr.) or low (8-hr.) deprivation group.

The second phase of the experiment consisted of 4 days of testing, with each pair placed in the arena for $3 \mathrm{~min}$. The rats were placed in the corner opposite the water bottle, and the total time each rat spent drinking was recorded. Before returning the subjects to their home cages where water was once again available, each rat was allowed a 3-min. period of habituation to the grooming chamber of the next phase of the experiment on each of the 4 days of arena testing.

Prior to Stage 3, all rats were given individual 3-min. exposure to the water bottle in the arena, followed by 30-min. ad-lib water in their home cages. This procedure was designed both to maintain familiarization with the arena and to bring all subjects to a relatively nondeprived state with respect to water consumption. Rats of each pair were then placed at opposite corners of the test chamber for a 10-min. interval for each of 4 days. The amount of time each rat engaged in grooming activity was recorded.

In the final stage, pairs of animals were retested in the arena under the same motivational state as in the second phase of the study, and the time each spent drinking recorded.

For the purposes of this study, the rats which spent the greater proportion of time grooming during the third state of the experiment (grooming chamber) were defined as dominant. In all cases, recorded data were converted into percentages of total time the rats were actually engaged in either drinking or grooming, respectively, by individuals of each pair.

\section{RESULTS}

Dominant rats, as measured by proportion of time spent grooming, also demonstrated this ascendant tendency in a competitive drinking situation. These observations are shown in Figure 1. However, the data also suggest that only for the animals on high deprivation was the water competition as strong or 
consistent an indicator of this dominance. Animals on relatively low water deprivation showed only mild competitive dominance while very thirsty dominant rats spent a proportion of time drinking comparable to the time spent grooming in a nondeprived state.

An analysis of variance of the time percentages yielded significant $F$ ratios for deprivation $(F=10.55, d f=$ $1 / 12, p<.01)$, days $(F=4.23, d f=11 / 132, p<.01)$, and the Deprivation $\times$ Days interaction $(F=2.38, d f=$ $11 / 132, p<.05)$.

FIG. 1. Percentages of time spent drinking and grooming by dominant rats of pairs as a function of testing sessions. (Data are percentages of total time spent on the particular activity under observation.)

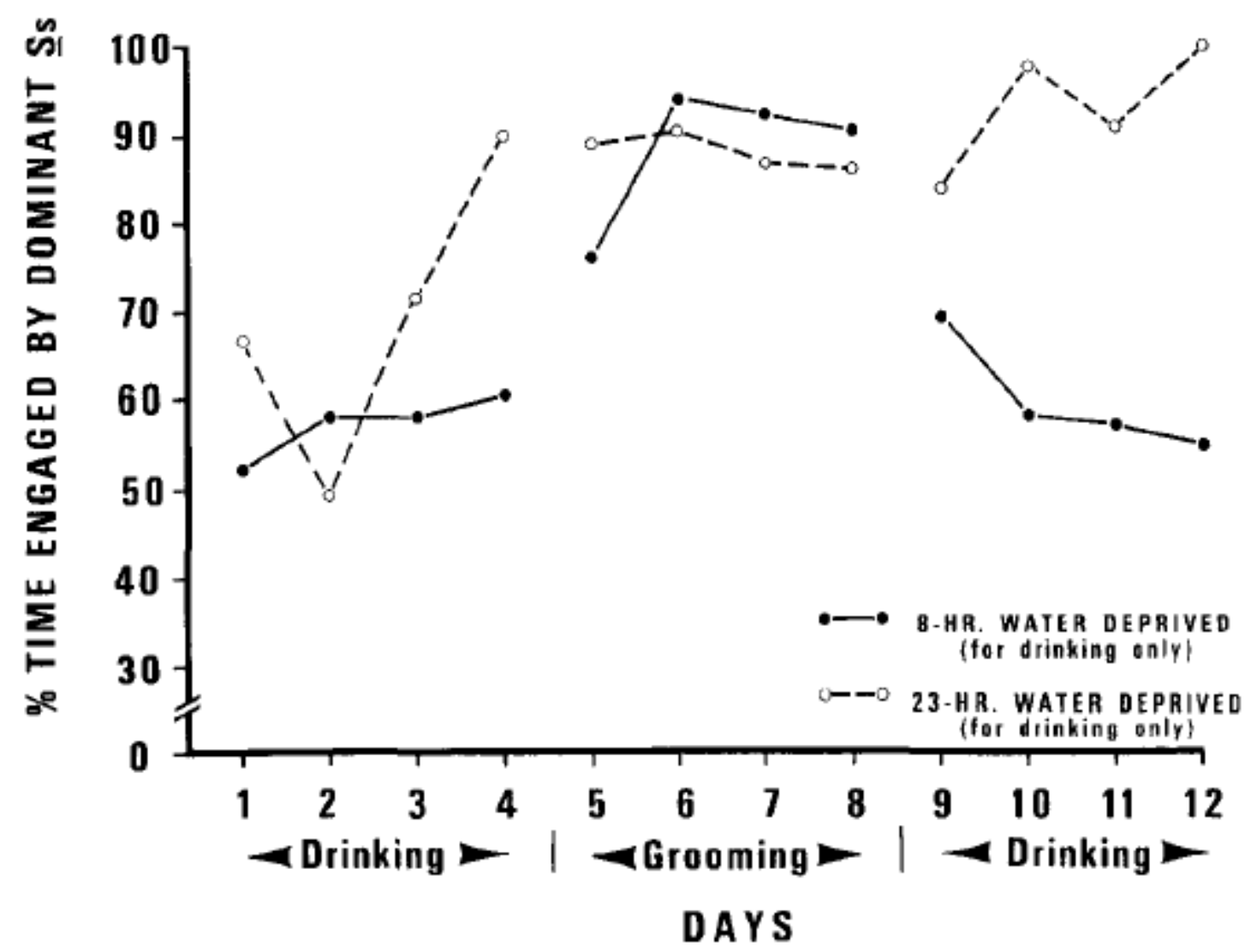

\section{DISCUSSION}

The results are consistent with the observations of Bruce (1941) and Hsiao and Schreiber (1968) which suggested that dominance was more readily manifest under higher motivational levels. It was quite apparent, in fact, that the rats on only 8-hr, deprivation showed relatively low competitive dominance in both test and retest in the water arena, while their grooming behavior was of the same high order as that of dominant rats which displayed extreme competitive ascendance under 23 -hr, deprivation.

In addition, the conclusion by Bruce (1941) that "competitive behavior does not appear when both animals can satisfy their drives at the same time [p. 411]" raises some interesting questions with respect to rat social behavior in the light of the current findings. Stage 3 of the present study clearly indicated the ascendancy of one member of a pair in a nondeprived social situation when grooming was taken as the 
dominance indicator. From both this finding, and the observations suggesting that most grooming is displayed by winners of fights, it would not be out of line to hypothesize the operational existence of a need to groom. This may now be explored within traditional paradigms designed to examine the effects of various antecedent social manipulations on the strength and persistence of such a need.

It would further appear from the current experiment that grooming behavior may be a strong and even more consistent index of social dominance which is relatively independent of unrelated biological states.

${ }^{\dagger}$ This research was supported by a grant from the National Research Council of Canada.

\section{REFERENCES}

BAENNINOEE, L. P. The reliability of dominance orders in rats. Animal Behaviour, 1966, 14, 367-371.

BAKNETT, S. A. A study in behavior. Chicago, Ill.: Aldine, 1967.

BECKER, G. Social dominance and subordination in the rat as a function of post-weaning electrical stimulation. Journal of Genetic Psychology, 1966, 107, 349-369.

BRUCE, R. H. An experimental analysis of social factors affecting the performance of white rats: III. Dominance and cooperation motivated by water and food deprivation. Journal of Comparative Psychology, 1941, 31, 395-412.

HSIAO, S., \& SCHREIBER, S. C. Social dominance and motivational variables in rats. Psychonomic Science, 1968, 10, 117-118.

INGEBOHG, L. W., \& GERALL, A. A. Dominance behavior in socially isolated rats. Psychonomic Science, $1968,13,39-40$.

LINDZEY, G., MANOSEVITZ, M., \& WINSTON, H. Social dominance in inbred mouse strains. Nature, 1961, 191, 474-476.

LINDZEY, G., MANOSEVITZ, M., \& WINSTON, H. Social dominance in the mouse. Psychonomic Science, 1966, 5, 451-452.

UYENO, E. T. Dominance behavior of rats under survival motivation. Psychonomic Science, 1971, 23, 24.

UYENO, E. T., \& WHITE, M. Social isolation and dominance behavior. Journal of Comparative and Physiological Psychology, 1967, 63, 157-159. 